\title{
MDR1 polymorphisms are associated with inflammatory bowel disease in a cohort of Croatian IBD patients
}

\author{
Marko Brinar ${ }^{1 *}$, Silvija Cukovic-Cavka ${ }^{1}$, Nada Bozina ${ }^{2}$, Katja Grubelic Ravic ${ }^{1}$, Pave Markos ${ }^{1}$, Agata Ladic ${ }^{1}$, \\ Marijana Cota ${ }^{3}$, Zeljko Krznaric ${ }^{1}$ and Boris Vucelic ${ }^{1}$
}

\begin{abstract}
Background: Inflammatory bowel diseases (IBD) are chronic diseases of unknown etiology and pathogenesis in which genetic factors contribute to development of disease. MDR1/ABCB1 is an interesting candidate gene for IBD. The role of two single nucleotide polymorphisms, C3435T and G2677T remains unclear due to contradictory results of current studies. Thus, the aims of this research were to investigate the association of MDR1 polymorphisms, C3435T and G2677T, and IBD.

Methods: A total of 310 IBD patients, 199 Crohn's disease (CD) patients and 109 ulcerative colitis (UC) patients, and 120 healthy controls were included in the study. All subjects were genotyped for G2677T/A and C3435T polymorphism using RT-PCR. In IBD patients, review of medical records was performed and patients were phenotyped according to the Montreal classification.

Results: Significantly higher frequency of $2677 \mathrm{~T}$ allele $(p=0.05 ; \mathrm{OR} 1.46,95 \% \mathrm{Cl}(1.0-2.14)$ ) and of the $3435 \mathrm{TT}$ genotype was observed among UC patients compared to controls ( $p=0.02 ; \mathrm{OR} 2.12 ; 95 \% \mathrm{Cl}(1.11-4.03)$. Heterozygous carriers for C3435T were significantly less likely to have CD ( $p=0.02$; OR 0.58, 95\% CI (0.36-0.91)). Haplotype analysis revealed that carriers of 3435T/2677T haplotype had a significantly higher risk of having UC $(\mathrm{p}=0.02 ; \mathrm{OR} 1.55 ; 95 \% \mathrm{Cl}(1.06-2.28))$.
\end{abstract}

Conclusion: MDR1 polymorphisms are associated with both CD and UC with a stronger association with UC.

Keywords: MDR1, Crohn's disease, Ulcerative colitis, IBD

\section{Background}

Inflammatory bowel disease (IBD) encompasses Crohn's disease $(\mathrm{CD})$ and ulcerative colitis (UC). Both $\mathrm{CD}$ and $\mathrm{UC}$ are chronic inflammatory disorders of the gastrointestinal tract with a combined incidence of 2-20 per 100,000 in the developed world [1]. In recent years, considerable progress in the field of IBD genetics has led to identification of a number of genetic factors involved in the pathogenesis of the disease. However, the underlying pathogenesis of IBD remains unclear. It is presumed that both disorders result as a consequence of defective mucosal barrier and a dysregulated immune response to a

\footnotetext{
* Correspondence: marko.brinar@zg.t-com.hr

'Division of Gastroenterology and Hepatology, University Hospital Centre Zagreb, 10000, Zagreb, Croatia

Full list of author information is available at the end of the article
}

host's microbiota in genetically susceptible individual. In that respect, the multidrug resistance 1 (MDR1) gene, also known as adenosine triphosphate-binding cassette superfamily member $1(A B C B 1)$ is an interesting candidate gene for IBD for several reasons. $M D R 1$ encodes a transmembrane protein, P-glycoprotein 170 (Pgp) which functions as an ATP-dependent efflux transporter pump and is highly expressed in the epithelial surfaces of the intestine, biliary ductules, proximal tubules of kidneys and central nervous system [2-4]. Although its physiological substrate remains unknown, numerous, structurally different compounds, have been identified as a substrates of Pgp [5]. In the gut, Pgp is constitutively expressed on the apical surfaces of the superficial columnar epithelial cells in the intestine with levels of expression gradually rising from the duodenum to the distal 
parts of the intestine with the highest levels of expression in the distal small bowel and colon [6,7]. Although it physiological function in the gut remains unclear, such high levels of expression suggest not only a role in protection against xenobiotics but possibly a role in modulating host-bacterial interactions.

First clue to a possible role od MDR1 in IBD pathogenesis comes from a mouse model in which mdrla knockout mice develop colitis resembling ulcerative colitis in a specific, pathogen free enviroment, that can be alleviated by a course of antibiotics [8]. Furthermore, MDR1 is located within a region of suggestive IBD linkage on chromosome 7q [9]. Finally, MDR1 gene expression is significantly reduced in the colonic tissue of UC patients
[10]. These findings combined make MDR1 an excellent both positional and functional IBD candidate gene.

Two single nucleotide polymorphisms (SNP), namely the triallelic G2677T/A (rs2032582) in exon 21 and C3435T (rs1045642) in exon 26, have been shown to correlate with Pgp expression [11-14]. Association of these SNP's with both CD and UC, either as a single marker or combined has been extensively studied. However, following initial positive associations subsequent studies have yielded contradictory results [15-30] (Table 1).

In summary, $M D R 1$ is an excellent positional and functional candidate gene for IBD. However, inconsistent results of previous studies make its role in IBD controversial. It has to be noted that a vast majority of association

Table 1 Summary of MDR1 association studies

\begin{tabular}{|c|c|c|c|c|}
\hline Author & No of cases & Tested SNP & Population & Results \\
\hline \multirow[t]{2}{*}{ Schwab et al. } & 149 UC & C3435T & German & T allele associated with UC $(p=0.049)$ \\
\hline & $126 C D$ & & & \\
\hline \multirow[t]{2}{*}{ Croucher et al. } & 307 UC & C3435T & German \& British & No association \\
\hline & $562 C D$ & & & \\
\hline \multirow[t]{2}{*}{ Brant et al. } & 119 UC & C3435T G2677T & USA & G2677 associated with IBD $(p=0.003)$ \\
\hline & $409 C D$ & & & \\
\hline \multirow[t]{2}{*}{ Glas et al. } & $123 \cup C$ & C3435T & German & No association \\
\hline & $135 \mathrm{CD}$ & & & \\
\hline \multirow[t]{2}{*}{ Potocnik et al. } & $144 \cup C$ & Multiple intron, exon and & Slovenian & $2677 T$ associated with UC $(p=0.02) ;$ Risk and \\
\hline & $139 \mathrm{CD}$ & & & \\
\hline \multirow[t]{2}{*}{ Gazzouli et al. } & $85 \cup C$ & С3435T & Greece* $^{*}$ & No association \\
\hline & $120 \mathrm{CD}$ & & & \\
\hline \multirow[t]{2}{*}{ Ho et al. } & $335 \cup C$ & С $3435 \mathrm{~T}$ & Scottish & 3435T associated with UC $(p=0.02) ; 3435 T$ \\
\hline & $268 C D$ & G2677T & & associated with extensive colitis $(p=0.003)$ \\
\hline \multirow[t]{2}{*}{ Onnie et al. } & $580 \cup C$ & С $3435 \mathrm{~T}$ & British & 2677 T associated with UC $(p=0.03)$ \\
\hline & $828 \mathrm{CD}$ & G2677T & & \\
\hline \multirow[t]{2}{*}{ Urcelay et al. } & $330 \cup C$ & С $3435 \mathrm{~T}$ & Spanish* & C3435T CC genotype associated with CD \\
\hline & $321 C D$ & G2677T & & \\
\hline \multirow[t]{2}{*}{ Oostenbrug et al. } & $224 \cup C$ & С $3435 \mathrm{~T}$ & Dutch & No association \\
\hline & $533 \mathrm{CD}$ & & & \\
\hline \multirow[t]{2}{*}{ Lal et al. } & 112 UC & С $3435 \mathrm{~T}$ & Canadian & $3435 T$ allele associated with $C D(p=0.02)$ \\
\hline & $247 C D$ & & & \\
\hline \multirow[t]{2}{*}{ Fiedler et al. } & $144 \cup C$ & С $3435 \mathrm{~T}$ & German & No association \\
\hline & $244 C D$ & G2677T & & \\
\hline \multirow[t]{2}{*}{ Fischer et al. } & $149 \cup C$ & С $3435 \mathrm{~T}$ & Hungarian & No association \\
\hline & $265 C D$ & G2677T & & \\
\hline \multirow[t]{2}{*}{ Ardizzone et al. } & $97 \cup C$ & С $3435 \mathrm{~T}$ & Italian & No association \\
\hline & $211 C D$ & G2677T & & \\
\hline \multirow[t]{2}{*}{ Huebner et al. } & 401 UC & G2677T & New Zealand & G2677T protective for UC $(p=0.02)$ \\
\hline & $483 \mathrm{CD}$ & & & \\
\hline
\end{tabular}

* Data not in Hardy-Weinberg equilibrium. 
studies performed in Caucasians were done in North European populations known to have a higher incidence of IBD compared to regions of the Southern Europe suggesting possible genetic differences in these populations. Therefore, we aimed to investigate the association between MDR1 G2677T/A and C3435T SNP and susceptibillity for UC and CD in an independent cohort of Croatian IBD patients and healthy controls.

\section{Methods}

\section{Patients}

A total of $199 \mathrm{CD}$ patients and $109 \mathrm{UC}$ patients followed up for IBD in the University Hospital Centre Zagreb from 01.01.2006 to 31.12.2010. were included. In all cases diagnosis of IBD was established according to standard clinical, radiological, endoscopic and histology criteria. Patients with unclassified IBD (IBDU) were excluded from the study. Upon inclusion, clinical records were reviewed for gender, age at diagnosis, localization and behavior of disease, extraintestinal manifestations and need for surgery. Localization and behavior of disease were defined according to Montreal classification [31]. The clinical characteristics of patients studied are summarized in Tables 2 and 3.

A total of 120 age and sex-matched, unrelated, healthy volunteers recruited from the general population with no symptoms and no family history of IBD formed a

\section{Table 2 Clinical characteristics of CD patients}

\begin{tabular}{lc}
\hline Number of patients & 199 \\
Sex - no. of patients (\%) & $93(46.7)$ \\
Female & $106(53.3)$ \\
Male & $111(56.3)$ \\
$\quad$ Surgery - no of patients (\%) & $25.0[18.50-31.10]$ \\
Age at diagnosis (years), median & \\
[interquartile range] & $28.6[22.80-36.80]$ \\
Age at surgery (years), median & \\
[interquartile range] & $3.0[0.40-6.67]$ \\
Disease duration to surgery (years), \\
median [interquartile range] \\
Localization - no. of patients (\%) \\
Ileal \pm UGl \\
Colon \pm UGl \\
Ileocolon \pm UGl \\
UGl \\
UGl any & $34(32.2)$ \\
Behaviour - no. of patients (\%) & $98(47.1)$ \\
Inflammatory \pm perianal & $3(1.5)$ \\
Stricturing \pm perianal & $29(14.6)$ \\
Penetrating \pm perianal & \\
Perianal (any) & $89(45.4)$ \\
\hline & $65(33.2)$ \\
& $42(21.4)$ \\
& $70(35.4)$ \\
\hline
\end{tabular}

control group. All volunteers were questioned regarding IBD symptoms as well as for symptoms of other immune mediated diseases such as rheumathologic conditions and psoriasis. Informed consent was obtained from all patients and controls prior to inclusion and the study was approved by the Ethics Committee of the University Hospital Centre Zagreb.

\section{Genotyping}

Genomic DNA was extracted from peripheral lymphocytes using the salting out procedure [32]. MDR1 genotypes of all patients were determined. For the $M D R 1$ exon 21 G2677T/A, and exon 26 C3435T variants, a Real-time PCR methods were performed using LightCycler (Roche Applied Sciences, Indianapolis, IN) with the Fast Start DNA Master plus HybProbe Master Mix [33-35]. To prevent genotyping errors DNA samples were genotyped in duplicate by RealTime PCR based method. Also every tenth DNA sample was checked by another method based on PCR-RFLP.

\section{Statistics}

Basic group comparisons were performed using SPSS 17.0.1. (SPSS Inc., Chicago, IL) and Haploview 4.1. Differences in continuous variables were tested using the independent sample $t$-test and the Mann-Whitney $U$ test for normally and not normally distributed variables, respectively.

Allele and genotype frequencies were compared between groups using the $\chi^{2}$ or Fischer's exact test when appropriate. Two-sided $\mathrm{p}$ values along with odds ratios (OR) and $95 \%$ confidence intervals $(\mathrm{CI})$ were calculated. Haplotype frequencies were estimated using the expectationmaximization (EM) algorithm [36] implemented in Haploview 4.1. Due to the low frequency of the A allele of

\section{Table 3 Clinical charateristics of UC patients}

\begin{tabular}{lc}
\hline Number of patients & 109 \\
Sex - no. of patients (\%) & $57(52.3)$ \\
$\quad$ Female & $52(47.7)$ \\
$\quad$ Male & $21(19.8)$ \\
Surgery - no of patients (\%) & $29.9[26.0-35.70]$ \\
Median [interquartile range] age & \\
at diagnosis (yrs) & $37.3[31.80-43.10]$ \\
Median [interquartile range] age & \\
at surgery (yrs) & $4.4[1.0-7.75]$ \\
Median [interquartile range] disease & \\
duration at surgery (yrs) & \\
Localization - no. of patients (\%) & $11(10.2)$ \\
$\quad$ Proctitis & $22(20.4)$ \\
$\quad$ Left sided colitis & $75(69.4)$ \\
\hline Pancolitis &
\end{tabular}


the G2677T/A the carriers of that allele were excluded from further analysis. Significance was set at $\mathrm{p}<0.05$.

\section{Results}

Genotype analysis

Genotypes of both C3435T and G2677T/A were in Hardy-Weinberg equilibrium both in cases and in the control group. Distribution of allele and genotype frequencies for G2677T/A and C3435T SNP are listed in Table 4. We observed a trend toward higher frequency of the T allele of the C3435T SNP in UC patients compared to controls $(53.7 \%$ vs. $44.6 \% ; \mathrm{p}=0.051)$. In UC patients, a significantly higher frequency of the TT genotype was observed compared to controls $(28.7 \%$ vs. $16.0 \% ; \mathrm{p}=0.02$; OR 2.12; 95\% CI (1.11-4.03)) (Table 4). Marginally significant difference in the frequency of $2677 \mathrm{~T}$ allele was observed in UC patients compared to controls $(44.7 \%$ vs. $35.2 \%$; $\mathrm{p}=0.05$; OR $1.46,95 \% \mathrm{CI}$ (1.0-2.14)). No significant differences in genotype frequencies for G2677T SNP were observed in UC cases compared to controls. No significant differences in allele frequencies of C3435T and G2677T/A were observed in $\mathrm{CD}$ cases compared to controls. However, association was detected on genotypic level with heterozygous carriers for C3435T having a significantly lower risk of having CD $(\mathrm{p}=0.02$; OR $0.58,95 \%$ CI $(0.36-0.91))$. No significant differences in genotype frequencies for G2677T SNP were observed in CD cases compared to controls.

A high degree of linkage disequilibrium was observed between the two studied SNP's in our sample $\left(D^{\prime}=0.9\right)$. A significant difference in the frequency of carriers of $3435 \mathrm{~T} / 2677 \mathrm{~T}$ haplotype between UC cases and controls was observed with carriers of that haplotype having a significantly higher risk of having UC ( $\mathrm{p}=0.02$; OR 1.55 ; 95\% CI (1.06-2.28)) (Table 5). No significant differences in 2-locus haplotype frequencies were observed in $\mathrm{CD}$ cases compared to controls.

\section{Discussion}

In this study, we investigated the association of MDR1 polymorphisms and IBD in a cohort of well charaterized patients. We detected a significant association of C3435T and G2677T polymorphism and UC with higher frequency of mutant allele and/or genotype carriers in the UC patient group. In that respect, our results are in accordance with previously published results reporting the association of UC with G2677T and C3435T SNP $[15,17,20,21,23]$. Contrary to the previously published results, we detected no association of C3435T variant with pancolitis although a large proportion of our UC patient group had pancolitis (69.4\%) [21]. Furthermore, due to the high LD between the two studied SNP's, we were able to investigate the association with two-locus haplotypes. Previous studies reported both risk and protective haplotypes in the same cohort suggesting a complex influence of MDR1 in pathogenesis of disease [20,21]. We detected a significantly higher frequency of $3435 \mathrm{~T} / 2677 \mathrm{~T}$ haplotype carriers in the UC patient group. The same haplotype is also a part of two haplotypes associated with UC in the study by Potocnik et al. performed on Slovenian IBD patients [20].

We found no significant difference in allele distributions of investigated SNP's between CD patient group and controls. However, we detected a significant association of

Table 4 MDR1 C3435T and G2677T allele and genotype frequencies in CD, UC and control group

\begin{tabular}{|c|c|c|c|c|c|}
\hline & Controls $(n=120)$ & $C D(n=199)$ & $\mathrm{p}$ value & UC $(n=109)$ & $p$ value \\
\hline \multicolumn{6}{|l|}{ C3435T } \\
\hline \multicolumn{6}{|c|}{ Allele frequencies (\%) } \\
\hline Allele C & $132(55.5)$ & $208(52.5)$ & 0.47 & $100(46.3)$ & 0.051 \\
\hline Allele $T$ & $106(44.5)$ & $188(47.5)$ & & $116(53.7)$ & \\
\hline \multicolumn{6}{|c|}{ Genotype frequencies (\%) } \\
\hline $\mathrm{CC}$ & $32(26.9)$ & $61(30.8)$ & 0.52 & $23(21.3)$ & 0.35 \\
\hline $\mathrm{CT}$ & $68(57.1)$ & $86(43.4)$ & 0.02 & $54(50.0)$ & 0.29 \\
\hline$\pi$ & $19(16.0)$ & $51(25.8)$ & 0.05 & $31(28.7)$ & 0.02 \\
\hline \multicolumn{6}{|l|}{ G2677T/A } \\
\hline \multicolumn{6}{|c|}{ Allele frequencies (\%) } \\
\hline Allele G & $149(64.2)$ & $239(61.6)$ & 0.51 & $119(55.1)$ & 0.05 \\
\hline Allele T & $83(35.8)$ & $149(38.4)$ & & $97(44.9)$ & \\
\hline \multicolumn{6}{|c|}{ Genotype frequencies (\%) } \\
\hline GG & $47(40.5)$ & $82(42.3)$ & 0.72 & $33(30.5)$ & 0.16 \\
\hline GT & $55(47.4)$ & 75 (38.6) & 0.16 & $53(49.1)$ & 0.69 \\
\hline$\Pi \mathrm{T}$ & $14(12.1)$ & $37(19.1)$ & 0.11 & $22(20.4)$ & 0.10 \\
\hline
\end{tabular}


Table 5 Frequencies of two-locus MDR1 haplotypes in CD and UC cases and controls

\begin{tabular}{llllll}
\hline Haplotype & Controls (\%) & UC (n\%) & p value & CD (\%) & p value \\
\hline C3435/G2677 & $126(53.4)$ & $97(44.6)$ & 0.07 & $202(51.0)$ & 0.62 \\
$3435 T / 2677 T$ & $78(33.1)$ & $94(43.2)$ & $\mathbf{0 . 0 2}$ & $145(36.6)$ & 0.34 \\
$3435 T / G 2677$ & $28(11.9)$ & $23(10.5)$ & 0.69 & $43(10.9)$ & 0.765 \\
C3435/2677T & $6(2.6)$ & $4(1.7)$ & 0.56 & $6(1.5)$ & 0.405 \\
\hline
\end{tabular}

C3435T heterozygous carriers with CD. Carriers of this genotype were significantly less represented in the $\mathrm{CD}$ patient group suggesting a protective effect. How exactly a heterozygous state confers protection is hard to explain at this moment. However, the same genotype was also found to be protective in UC in the study by Huebner et al. [30]. In this study the investigators put forward an interesting hypothesis that heterozygous carriers of certain MDR1 variants are more resistant to certain bacterial infections [30]. This hypothesis is based on the data from other diseases, like cystic fibrosis or sickle cell anemia, where heterozygous advantage exists [30]. However, although appealing, this hypothesis still needs to be tested, especially on a functional level.

The G2677T polymorphism is a coding polymorphism resulting in substitution of alanine by serine in the Pgp amino acid sequence. Studies investigating the influence of this polymorphism on Pgp expression have reached conflicting results with Kim et al. reporting association of 2677T allele with higher levels of Pgp expression [14]. However, Kimchi-Sarfaty et al. reported no influence of this polymorphism on expression level and intracellular localisation of Pgp [37]. However, G2677T polymorphism might exert its effect not by influencing levels of expression of Pgp but by altering Pgp stability or affinity for a certain substrate. On the other hand, C3435T has been associated with low levels of Pgp expression in Caucasians [11]. Interestingly, the opposite was found in Japanese subjects emphasizing the interethnical differences in Pgp expression [12]. The association of C3435T with low levels of Pgp expression in caucasians is in concordance with data from animal models with $\mathrm{mdr}^{-/-}$developing colitis. Interestingly, C3435 $\mathrm{T}$ is a synonymous SNP not leading to change in amino acid sequence. The possible explanation of the association of a synonymous SNP with altered levels of Pgp expression was offered by finding of moderate reduction of Pgp mRNA stability associated with this SNP [38]. Another possible explanation lies in the high levels of linkage disequilibrium within the MDR1 gene with C3435T in linkage with the true causal variant [5].

In general, our results seem to be in accordance with some of the previously published studies $[15,17,20,21,23]$. However, in a multitude of studies no association of investigated SNP's and UC was found [16,18,19,22, $25,27,29]$. The reason for such variability of results in the literature is not clear, however population heterogeneity seems to be the most plausible explanation. In the published studies frequency of the $3435 \mathrm{~T}$ allele varied from $41 \%-65.3 \%$ in the UC patient group while frequency of $2677 \mathrm{~T}$ allele varied from 40\%-53\% [15-30]. Even greater variation of mutant allele frequency can be found in the respective control groups where $3435 \mathrm{~T}$ allele frequency varied from $37 \%-63 \%$ and $2677 \mathrm{~T}$ allele frequency varied from $40 \%-53 \%$ [15-30]. The importance of the mutant allele frequency is further emphasized by study by Glas et al. in which the investigators used two separate controls groups. Performing the association analysis with control group 1 that had a $3435 \mathrm{~T}$ allele frequency of $52.8 \%$ no significant association of the $3435 \mathrm{~T}$ allele and UC was found. However, when control group 2 was used for analysis with $3435 \mathrm{~T}$ allele frequency of 43.7 a significant association of $3435 \mathrm{~T}$ allele and UC was found [18]. Due to the fact that the differences in the minor allele frequencies between the IBD group and the control group are quite modest it is quite possible that differences in the minor allele frequencies of the tested SNP's in the controls groups account for the majority of different results in the literature regarding these two SNP's. Importantly, the frequency of $2677 \mathrm{~T}$ allele in our control group was $35.8 \%$ which represents the lowest frequency published to date in a European population. Interestingly, the frequency of $2677 \mathrm{~T}$ allele, in the ethnically similar, Slovenian control group in the study by Potocnik et al. was also among the lowest reported in the literature (40\%) [20]. Our study further emphasizes differences between various European populations and underscores the importance of replication of results of genetic studies in different ethnic groups.

Finally, our study had several weaknesses. IBD patients included in the study represent the IBD population of a tertiary refferal center. As a consequence, majority of patients have extensive disease, especially in the UC group. Therefore, we can not exclude the possibility of bias since our cohort does not include a large number of patients with limited disease of low activity. Furthermore, although we detected a significant association of tested SNP's with UC and CD, the magnitude of the effect is modest. Given our relatively small sample size, our study had only $43 \%$ power to detect the effect of this magnitude. Taking this into account, the results of our study, although generally in accordance with previous reports, must be interpreted with caution.

\section{Conclusion}

In conclusion, our results confirm the role of $M D R 1$ in both CD and especially in UC pathogenesis although the overall influence of MDR1 variants on disease susceptibility is modest. 


\section{Competing interests}

The authors declared that they have no competing interests.

\section{Authors' contributions}

MB collected and analyzed the data and drafted the manuscript. SCC designed the study, interpreted the data, critically revised the manuscript and approved the final version to be published. NB interpreted the data, drafted the manuscript, critically revised the manuscript and approved the final version to be published. KGR collected the data, critically revised the manuscript and approved the final version to be published. PM collected the data, critically revised the manuscript and approved the final version to be published. AL collected the data, critically revised the manuscript and approved the final version to be published. MC critically revised the manuscript and approved the final version to be published. ZK critically revised the manuscript and approved the final version to be published. BV critically revised the manuscript and approved the final version to be published.

\section{Author details}

'Division of Gastroenterology and Hepatology, University Hospital Centre Zagreb, 10000, Zagreb, Croatia. ${ }^{2}$ Clinical Institute for Laboratory Diagnosis, University Hospital Centre Zagreb, 10000, Zagreb, Croatia. ${ }^{3}$ Nuvisan, Zagreb, Croatia.

Received: 15 May 2012 Accepted: 18 March 2013

Published: 27 March 2013

\section{References}

1. Andres $P G$, Friedman LS: Epidemiology and the natural course of inflammatory bowel disease. Gastroenterol Clin North Am 1999, 28:81-255. vii.

2. Juliano RL, Ling V: A surface glycoprotein modulating drug pereability in Chinese hamster ovary cell mutants. Biochim Biophys Acta 1976, 455:152-162.

3. Thiebaut F, Tsuoro T, Hamada H, Gottesman MM, Pastan I, Willingham MC: Cellular localisation of the multidrug-resistance gene product P-glycoprotein in normal human tissues. Proc Natl Acad Sci USA 1987, 84:7735-7738.

4. Cordon-Cardo O, O'Brien JP, Casals D, Rittmen-Grauer L, Biedler JL, Melamed MR, Bertino JR: Multidrug-resistance gene (P-gylcoprotein) is expressed by endothelial cells at the blood-brain barrier sites. Procl Natl Acad Sci USA 1989, 86:695-698.

5. Ho GT, Moodie FM, Satsangi J: Multidrug resistance 1 gene (P-glycoprotein 170): an important determinant of gastrointestinal disease? Gut 2003, 52:759-766.

6. Fricker G, Drewe J, Huwyler J, Gutmann H, Beglinger C: Relevance of p-glycoprotein for the enteral absorption of cyclosporin A; in vitroin vivo correlation. Br J Pharmacol 1996, 118:1841-1847.

7. Chianale J, Vollrath V, Wielandt AM, Miranda S, Gonzalez R, Fresno AM, Quintana C, Gonzalez S, Andrade R, Guzman L: Differences between nuclear run-off and mRNA levels for multidrug resistance gene expression in the cephalocaudal axis of the mouse intestine. Biochim Biophys Acta 1995, 1264:369-376.

8. Panwala CM, Jones JC, Viney JL: A novel model of inflammatory bowel disease: mice deficient for the multiple drug resistance gene, mdr1a, spontanously develop colitis. J Immunol 1998, 161:5733-5744.

9. Van Heel DA, Fisher SA, Kirby A, Daly MJ, Rioux JD: Lewis CM; Genome scan meta-analysis group of the IBD International genetics consortium. Inflammatory bowel disease susceptibility loci defined by genome scan meta-analysis of 1952 affected relative pairs. Hum Mol Genet 2004, 13:763-770

10. Langmann T, Moehle C, Mauerer R, Scharl M, Liebisch G, Zahn A, Stremmel W, Schmitz G: Loss of detoxification in inflammatory bowel disease: dysregulation of pregnane X receptor target genes. Gastroenterology 2004, 127:26-40

11. Hoffmeyer S, Burk O, von Richter O, Arnold HP, Brockmöller J, Johne A, Cascorbi I, Gerloff T, Roots I, Eichelbaum M, Brinkmann U: Functional polymorphisms of the human mutidrug-resistance gene: multiple sequence variations and correlation of one allele with P-glycoprotein activity in vivo. Proc Natl Acad Sci USA 2000, 97:3473-3478.

12. Tanabe $M$, leiri I, Nagata $N$, Inoue $K$, Ito $S$, Kanamori $Y$, Takahashi M, Kurata $Y$, Kigawa J, Higuchi S, Terakawa N, Otsubo K: Expression of P-glycoprotein in human placenta: relation to genetic polymorphisms of the mutidrug resistance (MDR)-1 gene. J Pharmacol Exp Ther 2001, 297:1137-1143.
13. Nakamura T, Sakaeda T, Horinouchi M, Tamura T, Aoyama N, Shirakawa T, Matsuo M, Kasuga M, Okumura K: Effect of mutation (C3435T) at exon 26 of the MDR1 gene on expression level of MDR1 messenger ribonucleic acid in duodenal enterocytes of healthy Japanese subjects. Clin Pharmacol Ther 2002, 71:297-303.

14. Kim RB, Leake BF, Choo EF, et al: Identification of functionally variant MDR1 alleles among European Americans and African Americans. Clin Pharamcol Ther 2001, 70:189-199.

15. Schwab M, Schaeffeler E, Marx C, Fromm MF, Kaskas B, Metzler J, Stange E, Herfarth H, Schoelmerich J, Gregor M, Walker S, Cascorbi I, Roots I, Brinkmann U, Zanger UM, Eichelbaum M: Association between the C3434T MDR1 gene polymorphism and susceptibility for ulcerative colitis. Gastroenterology 2003, 124:26-33.

16. Croucher PJ, Mascheretti S, Foelsch UR, Hampe J, Schreiber S: Lack of association between the C3435T MDR 1 gene polymorphisms and inflammatory bowel disease in two independent Northern European populations. Gastroenterology 2003, 125:1919-1920.

17. Brant SR, Panhuysen Cl, Nicolae D, Reddy DM, Bonen DK, Karaliukas R, Zhang L, Swanson E, Datta LW, Moran T, Ravenhill G, Duerr RH, Achkar JP, Karban AS, Cho JH: MDR1 Ala893 polymorphism is associated with inflammatory bowel disease. Am J Hum Genet 2003, 73:1282-1292.

18. Glas J, Török HP, Schiemann U, Folwaczny C: MDR1 gene polymorphism in ulcerative colitis. Gastroenterology 2004, 126:367.

19. Gazouli M, Zacharatos P, Gorgoulis V, Mantzaris G, Papalambros E, Ikonomopoulos J: The C3435T MDR1 gene polymorphism is not associated with susceptibility for ulcerative colitis in Greek population. Gastroenterology 2004, 126:367-369.

20. Potocnik U, Ferkolj I, Glavač D, Dean M: Polymorphisms in mutidrug resistance 1 (MDR1) gene are associated with refractory Crohn disease and ulcerative colitis. Genes Immun 2004, 5:530-539.

21. Ho GT, Nimmo ER, Tenesa A, Fennell J, Drummond H, Mowat C, Arnott ID, Satsangi J: Allelic variations of the multidrug resistance gene determine susceptibility and disease behavior in ulcerative colitis. Gastroenterology 2005, 128:288-296.

22. Palmieri O, Latiano A, Valvano R, D'Incà R, Vecchi M, Sturniolo GC, Saibeni S, Bossa F, Latiano T, Devoto M, Andriulli A, Annese V: Multidrug resistance gene polymorphisms are not associated with inflammatory bowel disease and response to therapy in Italian patients. Aliment Pharmacol Ther 2005, 22(11-12):1129-1138.

23. Onnie CM, Fisher SA, Pattni R, Sanderson J, Forbes A, Lewis CM, Mathew $C G$ : Associations of allelic variants of the multidrug resistance gene (ABCB1 or MDR1) and inflammatory bowel disease and their effects on disease behaviour: A case control study and meta-analyis study. Inflamm Bowel Dis 2006, 12:263-271.

24. Urcelay E, Mendoza JL, Martín MC, Mas A, Martínez A, Taxonera C, Fernandez-Arquero M, Díaz-Rubio M, de la Cocha EG: MDR1 gene: Susceptibility in Spanish Crohn's disease and ulcerative colitis patients. Inflamm Bowel Dis 2006, 12:33-37.

25. Oostenbrug LE, Dijkstra G, Nolte IM, van Dullemen HM, Oosterom E, Faber KN, de Jong DJ, van der Linde K, te Meerman GJ, van der Steege G, Kleibeuker $\mathrm{JH}$, Jansen PL: Absence of association between the mutidrug resistance (MDR1) gene and inflammatory bowel disease. Scand J Gastroenterol 2006, 41:1174-1182.

26. Lal S, Stempak JM, Law C, Elkadri AA, Steinhart AH, Silverberg MS: Association between the C3435T polymorphism of the MDR1 gene and Crohn's disease. Inflamm Bowel Dis 2006, 12:1006.

27. Fischer S: Lakatos LP; Hungarian IBD Study Group, Lakatos L, Kovacs A, Molnar T, Altorjay I, Papp M, Szilvasi A, Tulassay Z, Osztovits J, Papp J, Demeter P, Schwab R, Tordai A, Andrikovics H. ATP-binding cassette transporter $A B C G 2$ (BCRP) and $A B C B 1$ (MDR1) variants are not associated with disease susceptibility, disease phenotype, response to medical therapy or need for surgery in Hungarian patients with inflammatory bowel disease. Scand J Gastroenterol 2007, 42:726-733.

28. Fiedler T, Büning C, Reuter W, Pitre G, Gentz E, Schmidt HH, Büttner J, Ockenga J, Gerloff T, Meisel C, Lochs H, Roots I, Köpke K, Johne A: Possible role of MDR1 two-locus genotypes for young-age onset ulcerative colitis but not Crohn's disease. Eur J Clin Pharmacol 2007, 63:917-925.

29. Ardizzone S, Maconi G, Bianchi V, Russo A, Colombo E, Cassinotti A, Penati C, Tenchini ML, Bianchi PG: Multidrug resistance gene 1 polymorphism and susceptibility to inflammatory bowel disease. Inflamm Bowel Dis 2007, 13:516-523. 
30. Huebner C, Browning BL, Petermann I, Han DY, Philpott M, Barclay M, Gearry R, McCulloch A, Demmers P, Ferguson LR: Genetic analysis of MDR1 and inflammatory bowel disease reveals protective effect of heterozygous variants for ulcerative colitis. Inflamm Bowel Dis 2009, 15:1784-1793.

31. Silverberg MS, Satsangi J, Ahmad T, et al: Toward an integrated clinical, molecular and serological classification of inflammatory bowel disease: report of a Working Party of 2005 Montreal World Congress of Gastroenterology. Can J Gastroenterol 2005, 19(Suppl A):5-36.

32. Miller $S A$, Dykes DD, Polesky HF: A simple salting out procedure for extracting DNA from human nucleated cell. Nucl Acid Res 1988, 16:1215.

33. Arjomand-Nahad F, Diefenbach K, Landt O, Gaikovitch E, Roots I: Genotyping of the triallelic variant G2677T/A in MDR1 using LightCycler with locked-nucleic-acid-modified hybridization probes. Anal Biochem 2004, 334:201-203.

34. Oselin K, Gerloff T, Mrozikiewicz PM, Pähkla R, Roots I: MDR1 polymorphisms G2677T in exon 21 and C3435T in exon 26 fail to affect rhodamine 123 efflux in peripheral blood lymphocytes. Fundam Clin Pharmacol 2003, 17:463-469.

35. von Ahsen N, Richter M, Grupp C, Ringe B, Oellerich M, Armstrong WW: No influence of the MDR-1 C3435T polymorphism or a CYP3A4 promoter polymorphism (CYP3A4-V allele) on dose-adjusted cyclosporin A trough concentrations or rejection incidence in stable renal transplant recipients. Clin Chem 2001, 47:1048-1052

36. Excoffier L, Slatkin M: Maximum-likelihood estimation of molecular haplotype frequencies in a diploid population. Mol Biol Evol 1995, 12:921-927.

37. Kimchi-Sarfaty C, Gribar JJ, Gottesman MM: Functional characterization of coding polymorphisms in the human MDR1 gene using a vaccinia virus expression system. Mol Pharmacol 2002, 62:1-6.

38. Wang $D$, Johnson AD, Papp AC, et al: Multidrug resistance polypeptide 1 (MDR1, ABCB1) variant $3435 \mathrm{C}>\mathrm{T}$ affects mRNA stability. Pharmacogenet Genomics 2005, 15:693-703.

doi:10.1186/1471-230X-13-57

Cite this article as: Brinar et al:: MDR1 polymorphisms are associated with inflammatory bowel disease in a cohort of Croatian IBD patients. BMC Gastroenterology 2013 13:57.

\section{Submit your next manuscript to BioMed Central and take full advantage of:}

- Convenient online submission

- Thorough peer review

- No space constraints or color figure charges

- Immediate publication on acceptance

- Inclusion in PubMed, CAS, Scopus and Google Scholar

- Research which is freely available for redistribution 